\title{
Truncated Edge Cuprous Oxide Cube Architecture for Reduction of Nitrophenols
}

\author{
Elizabeth Erasmus \\ Department of Chemistry, University of the Free State, Bloemfontein 9300, South Africa \\ Received 07 February 2020, revised 26 November 2020, accepted 24 December 2020
}

\begin{abstract}
Truncated cubic Cu-oxide nanocrystals with edge lengths of ca. $600 \mathrm{~nm}$ were prepared employing the low-cost copper (II) chloride as the precursor. XRD revealed that the truncated cubic $\mathrm{Cu}$-oxide nanocrystals are present in both the $\mathrm{Cu}^{\mathrm{I}}$ and $\mathrm{Cu}{ }^{0}$ state. $\mathrm{XPS}$ characterisation gives insight into the amount of each state present in the as-prepared, oxidised, reduced and recovered catalyst species. The catalytic activity of the truncated cubic Cu-oxide nanocrystals was tested for the reduction of nitrophenols using $\mathrm{NaBH}_{4}$. After one catalytic cycle of the reduction of 4-nitrophenol, the activity almost halved. The SEM images revealed that the recovered catalyst showed some disfigurement of the structure, and XPS confirmed the reduction of the $\mathrm{Cu}^{\mathrm{I}}$ to metallic $\mathrm{Cu}{ }^{0}$.
\end{abstract}

\section{KEYWORDS}

Cu-oxide, truncated cubic nanocrystal, nitrophenol, catalysis, X-ray photoelectron spectroscopy.

\section{Introduction}

Metal oxide nanostructures are of great interest due to their enhanced chemical, physical, optical, electromagnetic and electronic properties in contrast to bulk metal oxides. ${ }^{1-3}$ These improved properties render them to be very versatile for many uses in different technological applications, including the chemical-, pharmaceutical industries, water treatment, food technology, and energy. In addition, due to the structural stability and diversity, metal oxides are regarded as excellent heterogeneous supports for the active catalyst particles. Due to the variety of oxidation states the metal oxide can adopt, metal oxides can be catalytically active themselves, ${ }^{4}$ especially during redox reactions.

It has been shown that there is a correlation between low bandgap energy (energy required to stimulate a valence electron to turn into a conduction electron) and the catalytic activity of heterogeneous catalysts. ${ }^{5} \mathrm{Cu}$-oxides $\left(\mathrm{Cu}_{2} \mathrm{O}\right.$ and $\mathrm{CuO}$ ) have low bandgap energy, ca. 1.3-2.5 eV. They are known for their high catalytic activity, ${ }^{6}$ along with their non-toxic nature and affordability, cause these $\mathrm{Cu}$-oxides to be studied intensively. ${ }^{7}$ With the developments in colloidal synthesis, the control of size, shape, morphology, and composition of metal oxide nanoparticles is possible. Various symmetrical morphologies, including cubic, octahedral and rhombic dodecahedral $\mathrm{Cu}_{2} \mathrm{O}$ and $\mathrm{CuO}$ nanocrystals, have been prepared..$^{5-13}$ Additionally, structurally more complex versions of these well-defined symmetrical shapes, such as truncated octahedral and truncated cubes, can also be prepared. ${ }^{14-17}$ Since it is well known that controlled morphology is key in enhancing the catalytic properties of heterogeneous catalysts, ${ }^{18} \mathrm{Cu}_{2} \mathrm{O}$ and $\mathrm{CuO}$ nanocrystals catalyst with a definite shape and size can be prepared. This control allows for facet and morphologically dependant catalytic studies.

This study wanted to explore the use of $\mathrm{Cu}$-oxide nanocrystals with a definite shape and size for the catalytic reduction of various nitrophenols using $\mathrm{NaBH}_{4}$. Nitrophenols are among others side-products formed during the preparation of pesticides, herbicides and synthetic dyes ${ }^{19-21}$ which are hazardous to living organisms. Hydrogenation of these nitrophenols to aromatic

${ }^{*}$ To whom correspondence should be addressed

Email:_erasmuse@ufs.ac.za amines turn these environmentally redundant compounds into useful intermediates and precursors for pharmaceuticals, polymers, pigments and agrochemicals. ${ }^{22-24}$

The as-prepared catalyst's morphology and chemical composition/oxidation state on the surface was investigated by SEM, UV-vis, XRD, ATR FTIR and XPS, respectively. The structural and chemical stability/changes of the Cu-oxide nanocrystals upon oxidation, reduction, and catalytic activity were explored.

\section{Experimental}

\subsection{Chemicals}

The solid and liquid reagents (from Sigma-Aldrich and Merck) were used without purification. Double-distilled water was used where necessary. XPS data were recorded on a PHI 5000 Versaprobe system with a monochromatic $\mathrm{Al} \mathrm{Ka} \mathrm{X}$-ray source. The surface morphology and the elementary composition were investigated using a Shimadzu Superscan ZU SXX-550 electron microscope (SEM), coupled with an energy dispersive X-ray spectroscope (EDS). A Bruker Tensor 27 (equipped with a diamond crystal) was used to examine wavenumber positions with ATR-FTIR of the neat crystal. UV-Vis characterisation of the $\mathrm{Cu}$-oxide nanocrystals in suspension was measure on an Olis Clarity CCD UV/Vis Spectroscopic system. This system can measure the UV-Vis of suspended material since it can eliminate the effect of light scatter and thus allows accurate absorbance of turbulent solutions. It has an effective path length of $30 \mathrm{~cm}$; thus, the Beer-Lambert law does not apply. The XRD pattern of the prepared truncated cubic $\mathrm{Cu}$-oxide nanocrystals was recorded on a Bruker D8 Advance diffractometer, using a $\mathrm{Cu} \mathrm{Ka}$ radiation in the range $25-85^{\circ}$. The UV-Vis spectra of the kinetics were recorded in a Cary 50 Probe UV/Visible spectrophotometer.

\subsection{Preparations}

\subsubsection{Colloidal synthesis of truncated cubic $\mathrm{Cu}_{2} \mathrm{O}$}

The truncated cubic $\mathrm{Cu}_{2} \mathrm{O}$ was prepared by a modified method based on the method of Z. Zhang et al. ${ }^{5} \mathrm{CuCl}_{2}(298$ $\mathrm{mg}, 2.2 \mathrm{mmol}$ ) was dissolved in $175 \mathrm{ml}$ water. This solution was heated to $55^{\circ} \mathrm{C}$, and $17.5 \mathrm{ml}$ of a $2 \mathrm{M} \mathrm{NaOH}$ solution was added dropwise. The solution was allowed to stir for a further $30 \mathrm{~min}$ at $55^{\circ} \mathrm{C}$, followed by the dropwise addition of $17.5 \mathrm{ml}$ of $0.6 \mathrm{M}$ ascorbic acid. The solution was allowed to stir for a further $5 \mathrm{~h}$ 
at $55{ }^{\circ} \mathrm{C}$. The precipitate was filtered and washed with water. After drying in a vacuum oven, the product was obtained in $44 \%$ (138.5 mg) yield

\subsection{Reduction of nitrophenols using $\mathrm{NaBH}$}

$5 \mathrm{ml}$ Nitrophenols (200 ppm) was added to $70 \mathrm{ml}$ water in a round bottom flask. $5 \mathrm{ml}$ Freshly prepared $\mathrm{NaBH}_{4}(0.1 \mathrm{M}$, $19 \mathrm{mg}$ in $5 \mathrm{ml}$ water) was added to the water mixture. The time was started when $10 \mathrm{mg}$ of the truncated cubic $\mathrm{Cu}_{2} \mathrm{O}$ catalyst was added. A UV-Vis spectrum was collected at suitable time intervals.

\section{Results and Discussion}

The truncated cubic $\mathrm{Cu}$-oxide nanocrystals were prepared by a colloidal synthesis procedure using ascorbic acid to direct structure growth. The hybrid morphological features of these $\mathrm{Cu}$-oxide nanocrystals could be determined from Scanning Electron Microscopy (SEM) images, see Figure 1 (Left). The truncated cubic $\mathrm{Cu}$-oxide is enclosed by six $\{100\}$ facets on the basal planes of the cube, while twelve $\{110\}$ facets enclose the edges of the cube and eight $\{111\}$ facets are located on the corners (see Figure 1 (middle) for a cartoon illustrating this). These $\mathrm{Cu}$-oxide nanocrystals are monodispersed and fairly uniform, with an average edge length of $600 \mathrm{~nm}$ (see the Supplementary Information (Fig. 1S) for the histogram and related data)

The crystallinity and phase purity of the truncated cubic $\mathrm{Cu}$ oxide nanocrystals were analysed by X-ray Diffraction (XRD). The XRD pattern of the Cu-oxide nanocrystals is present in Figure 1 (Right). The reflections at $29.1^{\circ}, 35.9^{\circ}, 41.8^{\circ}, 52.0^{\circ}$, $60.9^{\circ}, 73.1^{\circ}$ and $76.9^{\circ}$ are attributed to the $\{110\},\{111\},\{200\}$, $\{211\},\{220\},\{311\}$ and $\{222\}$ facets of the truncated cubic Cuoxide, respectively. The reflections are at slightly lower degrees (ca. $0.5^{\circ}$ ) than that found for cubic $\mathrm{Cu}_{2} \mathrm{O}_{1}^{25}$ which is attributed to the structure having the truncated system. The presence of the truncated cubic $\mathrm{Cu}$-oxide nanocrystals in the $\mathrm{Cu}_{2} \mathrm{O}$ form was confirmed. However, a small amount of $\mathrm{Cu}^{0}$ was also detected at $34.7^{\circ}, 41.9^{\circ}, 52.2^{\circ}$ and $73.3^{\circ}$ in correlation to published results. ${ }^{26}$ The peak relating to the $\mathrm{Cu}^{0}$ appeared as a small shoulder of the main peak resulting from the $\mathrm{Cu}_{2} \mathrm{O}$ form (see insert Figure 1 (Right)). This peak indicates that the truncated cubic $\mathrm{Cu}$-oxide nanocrystals are not exclusively present in the $\mathrm{Cu}^{\mathrm{I}}$ state but that some $\mathrm{Cu}^{0}$ is also present. No $\mathrm{CuO}\left(\mathrm{Cu}^{\mathrm{II}}\right.$ state) was detected since no peak was detected at $c a .32 .5^{\circ}$, which is the position where the strong $\{110\}$ peak appears. ${ }^{27}$ X-ray photoelectron spectroscopy (XPS) analysis was conducted on the truncated cubic $\mathrm{Cu}$-oxide nanocrystals sample to confirm this finding further.

XPS was used to determine the atomic composition and oxidation state of the copper and the ratio of the different atomic species present on the surface of the nanocrystals. The wide scan spectra (showing all the elements present) is given in the Supplementary Information (Figure S2 (A)). These photoelectron lines were charge corrected by shifting the spectra so that the lowest binding energy of the simulated
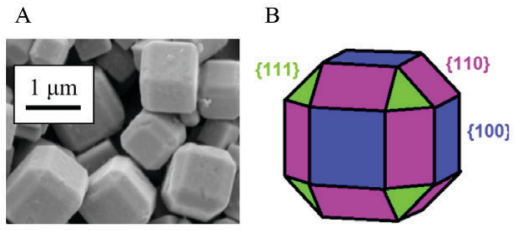

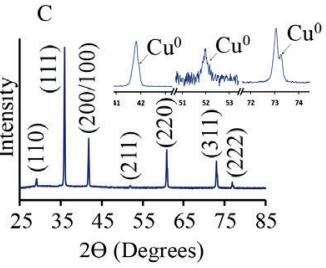

Figure 1 The SEM images (A), a cartoon indicating the facets enclosing the particle $(B)$ and the XRD pattern $(C)$ of the as-prepared truncated cubic $\mathrm{Cu}$-oxide nanocrystals.- adventitious carbon C 1s photoelectron line is set at $284.8 \mathrm{eV}$. The peak maximum of the $\mathrm{Cu} 2 \mathrm{p}$ envelopes were found at ca. 932 and $952 \mathrm{eV}$ for the $\mathrm{Cu} 2 \mathrm{p}_{3 / 2}$ and $\mathrm{Cu} 2 \mathrm{p}_{1 / 2}$ photoelectron lines, with small shake-up features at $c a .10-12 \mathrm{eV}$ higher than the main photoelectron lines (Figure S2 (B)). These shake-up features typically correspond to the presence of $\mathrm{Cu}^{\mathrm{II}}$, either as $\mathrm{CuO}$ or $\mathrm{Cu}(\mathrm{OH})_{2}$. Due to the difficulty distinguishing between metallic $\mathrm{Cu}, \mathrm{Cu}^{\mathrm{I}}\left(\right.$ in $\mathrm{Cu}_{2} \mathrm{O}$ ) and $\mathrm{Cu}^{\mathrm{II}}$ (in $\mathrm{CuO}$ or $\left.\mathrm{Cu}(\mathrm{OH})_{2}\right)$, the curve fitting parameter proposed by Biesinger ${ }^{28}$ was employed to identify the species present. The visual representation of the simulated curve-fitting parameters used (relative binding energy, relative ratio of Full Width at Half Maximum and relative atomic \%) as per $\mathrm{Cu}$ species is presented in Figure 2 (A). Simultaneously, the Table with the numerical data can be found in reference no. 28. The simulated fits imposed on the XPS data of the as-prepared truncated cubic $\mathrm{Cu}$-oxide nanocrystals using the fitting parameters of Biesinger are shown in Figure 2 (B), and the data are summarised in Table 1 . This fit confirms the XRD data, where metallic $\mathrm{Cu}$ (most probably inside the particle) and $\mathrm{Cu}_{2} \mathrm{O}$ (in the $\mathrm{Cu}^{\mathrm{I}}$ state) covering the outside of the particle is present. $\mathrm{Cu}(\mathrm{OH})_{2}$ (in the $\mathrm{Cu}^{\mathrm{II}}$ state) was also observed in the XPS. However, the XRD analysis did not detect the characteristic peaks of $\mathrm{Cu}(\mathrm{OH})_{2}$ (strongest peak presents at $\left.c a .31 .2^{\circ}\right){ }^{29}$ The relative percentages of the different species present are $52.0 \%$ of $\mathrm{Cu}_{2} \mathrm{O}, 30.9 \% \mathrm{Cu}^{0}$ and $17.1 \% \mathrm{Cu}(\mathrm{OH})_{2}$.

In literature, it has been described that $\mathrm{Cu}_{2} \mathrm{O}(\mathrm{Cu}(\mathrm{I}))$ nanoparticles can be oxidised to $\mathrm{CuO}(\mathrm{Cu}(\mathrm{II}))$ upon exposure to air. ${ }^{30}$ This oxidation is reported to be size-dependent; the smaller the nanoparticles, the more reactive they are for oxidisation in

A

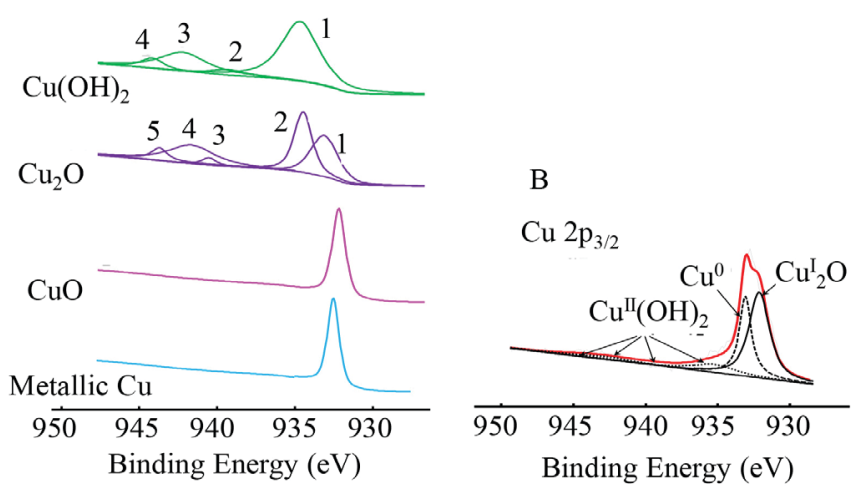

Figure 2 (A) A graphical representation of the simulated fitting parameters suggested by Biesinger ${ }^{28}$ the simulated fitted peaks in the spectra of $\mathrm{Cu}(\mathrm{OH})_{2}$ and $\mathrm{CuO}$ shows the numerical labels used to assign the XPS binding energy data presented in Table 1. (B) The detail XPS scan of the $\mathrm{Cu} 2 \mathrm{p}_{3 / 2}$ area of the truncated $\mathrm{Cu}$-oxide nanocrystals, showing the simulated fittings.

Table $1 \mathrm{Cu} 2 \mathrm{p}_{3 / 2}$ simulated curve-fitting parameters of the as-prepared truncated cubic Cu-oxide nanocrystals after treatment with $\mathrm{NaBH}_{4}$. The numerical peaks labels correlate with the simulated fitted peaks in $\mathrm{Cu}(\mathrm{OH}) 2$ and $\mathrm{CuO}$ spectra shown in Figure 2 .

\begin{tabular}{lccc}
\hline & As prep & $\mathrm{NaBH}_{4}$ \\
\hline $\mathrm{BE} \mathrm{Cu}{ }_{2}{ }^{\mathrm{O}}(\mathrm{eV})$ & & 932.1 & \\
$\%$ ratio & & 52.0 & \\
$\mathrm{BE} \mathrm{Cu}(0)(\mathrm{eV})$ & & 933.0 & 932.56 \\
$\%$ ratio & Peak 1 & 935.9 & 100 \\
& Peak 2 & 939.8 & \\
$\mathrm{BE} \mathrm{Cu}$ & \\
& Peak 3 & 942.7 & \\
Total \% ratio & Peak 4 & 944.7 & \\
& & 17.1 & \\
\hline
\end{tabular}


air. It is also mentioned that bulk $\mathrm{Cu}_{2} \mathrm{O}$ is not stable in air at room temperature and can easily be oxidised. However, this stability was not observed for the truncated cubic $\mathrm{Cu}$-oxide nanocrystals (average edge length $600 \mathrm{~nm}$ ) as verified by the absence of $\mathrm{Cu}(\mathrm{II})$ in the XPS and XRD. The O 1s oxygen peak of the truncated cubic $\mathrm{Cu}$-oxide nanocrystals was also fitted with the suggested simulation parameters of Biesinger, ${ }^{28}$ see Figure $\mathrm{S} 3$ in the Supplementary Information. The O 1s photoelectron line of the $\mathrm{Cu}_{2} \mathrm{O}$ and $\mathrm{Cu}(\mathrm{OH})_{2}$ was found at 530.4 and $531.8 \mathrm{eV}$, respectively.

The UV-Visible spectra of the Cu-oxide nanocrystals suspended in water exhibited a broad absorption peak with two local maximum points located at 454 and $472 \mathrm{~nm}$ (see Figure 3, A). The latter compares very well with the reported wavelength of maximum absorption of cubic $\mathrm{Cu}$-oxide suspended in ethanol, found at $470 \mathrm{~nm}^{31}$

The classical Tauc equation ${ }^{32}$ was employed to determine the apparent bandgap energy, $E_{\mathrm{g}}{ }^{\prime}$, of the $\mathrm{Cu}$-oxide nanocrystals (the term apparently is used since this is not a thin film but nanocrystals):

$$
\alpha E_{\mathrm{p}}=K\left(E_{\mathrm{p}}-E_{\mathrm{g}}\right)^{1 / 2}
$$

where $\alpha$ is the absorption coefficient $(\alpha=\ln (\mathrm{T} / \mathrm{d})$, where $\mathrm{T}=$ transmission and $\mathrm{d}=$ thickness, average edge length was used in this case), $K$ is a constant, $E_{\mathrm{p}}$ is photon energy $\left(E_{\mathrm{p}}=h \mathrm{c} / \lambda\right.$, $h=$ Planck's constant and $\mathrm{c}=$ speed of light), and $E_{\mathrm{g}}$ is the bandgap energy. The extrapolated value $\left(E_{\mathrm{p}}\right.$ at $\left.\alpha=0\right)$ of the straight line to the $X$-axis of the graph of $\left(\alpha E_{p}\right)^{2}$ versus $E_{p}$ represents the apparent bandgap energy, which was found to be $E_{\mathrm{g}}^{\prime}=2.07 \mathrm{eV}$ (see Figure S4 in the Supplementary Information).

${ }^{g}$ Figure 3 (B) shows the ATR FTIR spectrum of truncated cubic $\mathrm{Cu}$-oxide nanocrystals. The transmittance frequency peak at $1105 \mathrm{~cm}^{-1}$ is attributed vibrational band of the $-\mathrm{O}-\mathrm{H}$ group (of $\left.\mathrm{Cu}(\mathrm{OH})_{2}\right)$, in correlation with published results. ${ }^{33}$ The presence of this peak further confirms that $\mathrm{Cu}(\mathrm{OH})_{2}$ is present in the sample. The lower frequency peaks at $700 \mathrm{~cm}^{-1}$ and $607 \mathrm{~cm}^{-1}$ are assigned to the $\mathrm{Cu}-\mathrm{O}$ stretching frequency in $\mathrm{Cu}_{2} \mathrm{O}^{34,35}$

The nanocrystals were exposed to $\mathrm{NaBH}_{4}$ to investigate the reduction of the $\mathrm{Cu}^{\mathrm{I}}$ present in the $\mathrm{Cu}_{2} \mathrm{O}$ to metallic $\mathrm{Cu}^{0}$.
Furthermore, since the model catalytic type reactions that will be tested is the reduction of nitrophenols with $\mathrm{NaBH}_{4}$, the influence of the $\mathrm{NaBH}_{4}$ on the $\mathrm{Cu}$-oxide nanocrystals is important. The same experimental conditions as during the catalysis were applied except that the nitrophenols were absent $(10 \mathrm{ml}$ of a $6.25 \mathrm{mM} \mathrm{NaBH}_{4}$ solution was added to a $70 \mathrm{ml}$ suspension of the Cu-oxide nanocrystals $(10 \mathrm{mg})$ ). The SEM image indicates that individual cubic structures were maintained. However, the well-defined edges had been smoothed (Figure 4(A)). As for the chemical composition (as measured by XPS, see Figure 4 (B) for the $\mathrm{Cu} 2 \mathrm{p}_{3 / 2}$ area), the $\mathrm{Cu}^{\mathrm{I}}$ converted $100 \%$ to metallic $\mathrm{Cu}^{0}$ with the new binding energy at $932.56 \mathrm{eV}$.

The heterogeneous catalytic activity of the truncated cubic $\mathrm{Cu}$-oxide nanocrystals, with sodium borohydride $\left(\mathrm{NaBH}_{4}\right)$, was evaluated for the reduction of three different nitrophenols. The nitrophenols under investigation were 2-, 3- and 4-nitrophenol. The time-dependent absorption curves (Figure 5) show a decrease in the absorption at the peak maxima in the visible region. Manipulation of the data resulted in the construction of the absorption vs time (at the wavelength of peak maxima) and $\ln \left(\mathrm{A} / \mathrm{A}_{0}\right)$ vs time graphs (Figure 5). The later graph exhibited a linear relationship, having a negative slope. The absolute value of the slope is the apparent pseudo-first-order rate constant (see Table 2 for the average of the experiment done in triplicate), ${ }^{36}$ which will be used to compare the reduction rates of the different nitrophenols. The order of reactivity from slowest to fastest is:

\section{4-Nitrophenol $<3$-Nitrophenol $<2$-Nitrophenol}

Comparison of the apparent pseudo-first-order rate constant, $k^{\prime}$, with the Hammett constants (an empirical value relating the reaction rates and equilibrium constants of meta- and parasubstituted aromatic compounds) $)^{37}$ of the different nitrophenol revealed a linear relationship (see Table 2 for the data and Fig. $5 \mathrm{~S}$ in the Supplementary Information for the graph). This relationship showed that an increase in the Hammett constant is associated with an increase of $k^{\prime}$. A higher Hammett constant is associated with a stronger electron-withdrawing effect (implying more electron density on the nitro-group). This
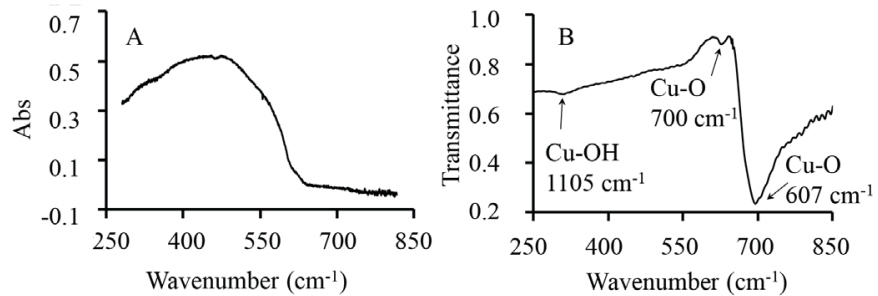

Figure 3 (A) The UV-Visible spectra of the truncated cubic $\mathrm{Cu}$-oxide nanocrystals (1 mg/8 ml water). (B) ATR FTIR spectrum of neat truncated cubic $\mathrm{Cu}$-oxide nanocrystals.
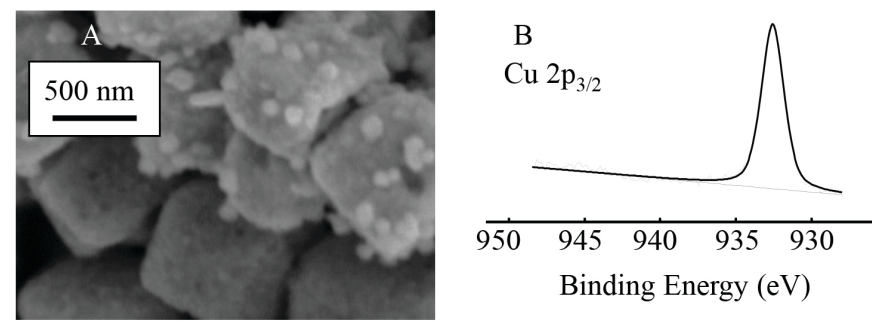

Figure 4 (A) The SEM images of the truncated cubic $\mathrm{Cu}$-oxide nanocrystals after exposure to $\mathrm{NaBH}_{4}$. (B) The detailed XPS of the $\mathrm{Cu}$ $2 \mathrm{p}_{3 / 2}$ region of the truncated cubic $\mathrm{Cu}$-oxide nanocrystals after exposure to $\mathrm{NaBH}_{4}$.
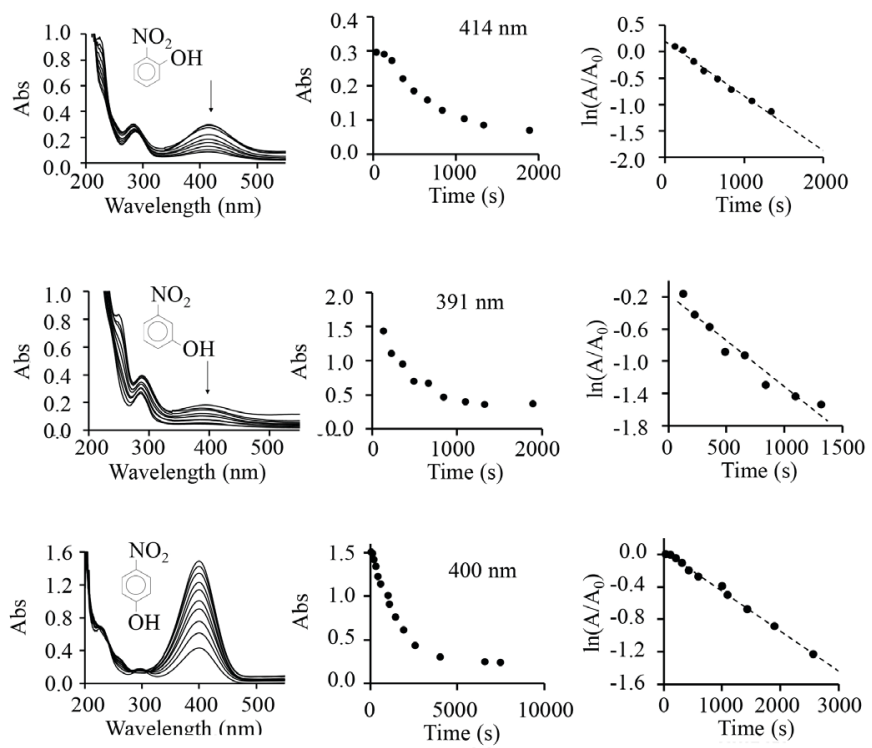

Figure 5 The UV-Vis absorption spectra over time, the graph of absorption vs time at the given wavelength and the graphs of the $\ln (\mathrm{A} /$ $A_{0}$ ) vs time (from which the apparent rate constants were calculated for comparison) for the catalytic reduction of 2-, 3- and 4-nitrophenol over the truncated cubic Cu-oxide nanocrystals using $\mathrm{NaBH}_{4}$ as the reducing agent. 
Table 2 Kinetic data of the comparative study of the catalytic reduction of 2-, 3- and 4-nitrophenol over the truncated cubic $\mathrm{Cu}$-oxide nanocrystals using $\mathrm{NaBH}_{4}$ as the reducing agent, showing the wavelength at the measured peak maxima $(\mathrm{nm})$ and the apparent pseudo-first-order rate constant, $k^{\prime},\left(\mathrm{s}^{-1}\right)$. The Hammett constants of the nitro groups in different positions on the aromatic ring are also tabulated.

\begin{tabular}{lccc}
\hline Nitrophenols & $\begin{array}{c}\text { Wavelength } \\
(\mathrm{nm})\end{array}$ & $\begin{array}{c}\text { Apparent } \\
\text { pseudo-first-order } \\
\text { rate constant, } k^{\prime},\left(\mathrm{s}^{-1}\right)\end{array}$ & $\begin{array}{c}\text { Hammett } \\
\text { constants }^{38}\end{array}$ \\
\hline 2-Nitrophenol & 414 & $1.16 \times 10^{-3}$ & 1.24 \\
3-Nitrophenol & 391 & $5.72 \times 10^{-4}$ & 0.71 \\
4-Nitrophenol & 400 & $5.11 \times 10^{-4}$ & 0.78 \\
\hline
\end{tabular}

effect suggests that the larger electron density causes faster reduction rates of the nitrophenol (over the truncated cubic Cu-oxide nanocrystals using $\mathrm{NaBH}_{4}$ as the reducing agent). These reduction rates are due to the easier nucleophilic attack of the oxygen (of the nitro group) on the $\mathrm{H}^{+}$, caused by the increased electron density. This attack trend is similar to what was obtained for the electrochemical reduction of nitrophenol with the nitro groups in different positions. ${ }^{38}$

The apparent pseudo-first-order rate constants halved when the recovered catalyst (truncated cubic $\mathrm{Cu}$-oxide nanocrystals) was used for a second catalytic cycle. After one catalytic cycle, the recovered catalyst's SEM image revealed that the particles retain their global cubic structure, but the planes and edge are no longer smooth (Figure 6, (A)). This reduced smoothness corresponds to the surface degradation of the truncated cubic $\mathrm{Cu}$-oxide nanocrystals exposed to $\mathrm{NaBH}_{4}$ (see Figure 4). This loss in the catalytic activity of the truncated cubic $\mathrm{Cu}$-oxide nanocrystals correlates to the literature ${ }^{39}$, where it was reported that cubic $\mathrm{Cu}$-oxide nanocrystals showed a significant loss in catalytic activity (for an oxidative arylation reaction) after the first cycle, from $94 \%$ to $47 \%$ yield. Li et al. ${ }^{39}$ also found the degradation of the straight edges attributed to the dissolution and reconstruction of active atoms at corners or edges during catalysis. In analogue to this, it is proposed that during the catalytic reduction of nitrophenol, some of the active $\mathrm{Cu}$-oxide fragments break away from the truncated cubic $\mathrm{Cu}$-oxide nanocrystals. Subsequently, these smaller particles aggregate randomly to the large $\mathrm{Cu}$-oxide particle. The decreased activity of truncated cubic $\mathrm{Cu}$-oxide nanocrystals could be due to the loss of active atoms into the reaction mixture.

After the second catalytic cycle, the SEM image showed that needle-like nanostructures protrude from the surfaces of the rough "cubic" structures (Figure 6 (B)). XPS measurements of the recovered catalysts revealed that only metallic $\mathrm{Cu}^{0}$ (binding energy $\mathrm{Cu} 2 \mathrm{p}_{3 / 2}=932.56 \mathrm{eV}$ ) was present in the recovered catalyst sample. Similar to when the truncated cubic $\mathrm{Cu}$-oxide nanocrystals were treated with $\mathrm{NaBH}_{4}$, and there was no evidence of $\mathrm{Cu}^{\mathrm{I}}$ of $\mathrm{Cu}^{\mathrm{II}}$ species in the materials.
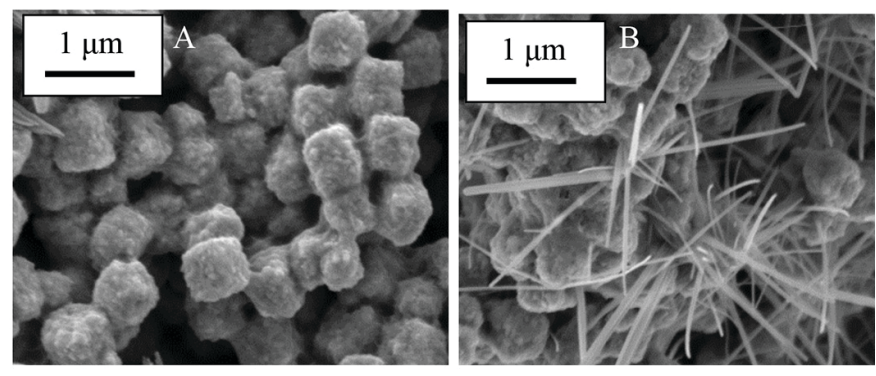

Figure 6 (A) The truncated cubic Cu-oxide's SEM images after one cycle and (B) two cycles of catalytic reduction of 4-nitrophenol using $\mathrm{NaBH}_{4}$.

\section{Conclusion}

Herewith we have disclosed the successful preparation of truncated cubic $\mathrm{Cu}$-oxide nanocrystals with a ca. $600 \mathrm{~nm}$ edge length. The detailed morphologies of the polyhedral structures were characterised by XRD and SEM, while the chemical and physical properties were analysed by UV-Vis, ATR FTIR, and XPS.

The XRD pattern indicates that the truncated cubic $\mathrm{Cu}$-oxide nanocrystals are not exclusively present in the $\mathrm{Cu}^{\mathrm{I}}$ state but that some $\mathrm{Cu}^{0}$ is also present. The XPS confirmed this presence, revealing some $\mathrm{Cu}^{\mathrm{II}}$ present in the $\mathrm{Cu}(\mathrm{OH})_{2}$ form. The structure and chemical composition are unstable towards exposure to the reducing agent $\mathrm{NaBH}_{4}$. Treatment with $\mathrm{NaBH}_{4}$ reduced the $\mathrm{Cu}^{\mathrm{I}}$ fully to metallic $\mathrm{Cu}^{0}$. The sharp and well-defined facets of the truncated cubic structure's edge and corners were lost and became round.

The truncated cubic $\mathrm{Cu}$-oxide nanocrystals can be used as a catalyst for reducing a variety of different nitrophenols. The order of reactivity from slowest to fastest is:

\section{4-Nitrophenol < 3-Nitrophenol < 2-Nitrophenol}

A directly proportional relationship was obtained between the pseudo-first-order rate constant, $k^{\prime}$, and the Hammett constants of the different nitrophenol. This relationship implies that an increase in the electron-withdrawing ability of the nitrophenol (higher Hammett constant) results in a faster reaction (an increase of $k^{\prime}$ ).

The recovered catalyst was found to be in the metallic $\mathrm{Cu}^{0}$ state, which was not as active as the $\mathrm{Cu}_{2} \mathrm{O}$ state. The structure deformed from the truncated cube to a "fussy" cubic structure after one cycle. After a second cycle, the SEM revealed that needle-like nanostructures protrude from the surfaces of rough "cubic" structures.

\section{Acknowledgements}

The author would like to acknowledge generous financial support from Sasol and the UFS during this study. Dr Shaun Cronjé from the Physics Department at the UFS is acknowledged for the XRD measurements.

\section{Supplementary Material}

Supplementary information for this article is provided in the online supplement.

\section{ORCID iD}

Elizabeth Erasmus: https://orcid.org/0000-0003-0546-697X

\section{References}

1 M. Kazes, D. Y. Lewis, and U. Banin, Method for preparation of semiconductor quantum-rod lasers in a cylindrical microcavity, Adv. Funct. Mater., 2004, 14(10), 957-962. DOI: 10.1002/adfm.200400018.

2 J. Choi, Y. Jun, S.-I. Yeon, H. C. Kim, J.-S. Shin, and J. Cheon, Biocompatible heterostructured nanoparticles for multimodal biological detection, J. Am. Chem. Soc., 2006, 128(50) 15982-15983. DOI: $10.1021 /$ ja066547g.

3 C. $\mathrm{Xu}$ et al., $\mathrm{Au}-\mathrm{Fe}_{3} \mathrm{O}_{4}$ dumbbell nanoparticles as dual-functional probes, Angew. Chemie Int. Ed., 2008, 47(1), 173-176. DOI: 10.1002/ anie.200704392.

4 J. C. Vedrine, Metal Oxides in Heterogeneous Catalysis, 1st edn, Elsevier, Amsterdam, 2018.

5 A. Bean Getsoian, Z. Zhai, and A. T. Bell, Band-gap energy as a descriptor of catalytic activity for propene oxidation over mixed metal oxide catalysts, J. Am. Chem. Soc., 2014, 136(39), 13684-13697. DOI: $10.1021 /$ ja5051555.

6 Y. Wang et al., Electronic structures of $\mathrm{Cu}_{2} \mathrm{O}, \mathrm{Cu}_{4} \mathrm{O}_{3}$, and $\mathrm{CuO}: \mathrm{A}$ joint experimental and theoretical study, Phys. Rev. B, 2016, 94(24), p. 245418. DOI: 10.1103/PhysRevB.94.245418.

7 L. Yu, X. Y. Yu, and X. W. D. Lou, The design and synthesis of hollow micro-/nanostructures: present and future trends, Adv. Mater., 2018, 


\section{0(38), 1800939. DOI: 10.1002/adma.201800939.}

8 T. Aditya, J. Jana, N. K. Singh, A. Pal, and T. Pal, Remarkable facet selective reduction of 4-nitrophenol by morphologically tailored (111) faceted $\mathrm{Cu}_{2} \mathrm{O}$ nanocatalyst, ACS Omega, 2017, 2(5), 1968-1984. DOI: 10.1021/acsomega.6b00447.

9 W. Huang, Oxide nanocrystal model catalysts, Acc. Chem. Res., 2016, 49(3), 520-527. DOI: 10.1021/acs.accounts.5b00537.

10 Y.-H. Won and L. A. Stanciu, $\mathrm{Cu}_{2} \mathrm{O}$ and $\mathrm{Au} / \mathrm{Cu}_{2} \mathrm{O}$ particles: surface properties and applications in glucose sensing, Sensors, 2012, 12(10), 13019-13033. DOI: 10.3390/s121013019.

11 Y. Zhang, B. Deng, T. Zhang, D. Gao, and A.-W. Xu, Shape effects of $\mathrm{Cu}_{2} \mathrm{O}$ polyhedral microcrystals on photocatalytic activity, J. Phys. Chem. C, 2010, 114(11), 5073-5079. DOI: 10.1021/jp9110037.

12 X. Liang, L. Gao, S. Yang, and J. Sun, Facile synthesis and shape evolution of single-crystal cuprous oxide, Adv. Mater., 2009, 21(20), 2068-2071. DOI: 10.1002/adma.200802783.

13 Y. Sui et al., Low temperature synthesis of $\mathrm{Cu}_{2} \mathrm{O}$ crystals: Shape evolution and growth mechanism, Cryst. Growth Des., 2010, 10(1) 99-108. DOI: $10.1021 / \mathrm{cg} 900437 x$.

14 Z. Yang, S. Sun, C. Kong, X. Song, and B. Ding, Designated-tailoring on $\{100\}$ facets of $\mathrm{Cu}_{2} \mathrm{O}$ nanostructures: From pctahedral to its different truncated forms," J. Nanomater., 2010, 2010, 1-11, DOI: $10.1155 / 2010 / 710584$.

15 E. Erasmus, Morphology-dependent Ullmann C-O arylation using $\mathrm{Cu}_{2} \mathrm{O}$ nanocrystals, J. Nanomater., 2020, 2020, 1-7. DOI $10.1155 / 2020 / 6726170$.

$16 \mathrm{~J}$. Zeng et al., Facile synthesis of cubic cuprous oxide for electrochemical reduction of carbon dioxide, J. Mater. Sci., 2021, 56(2), 1255-1271. DOI: 10.1007/s10853-020-05278-y.

17 A. Aljaafari, N. Parveen, F. Ahmad, M. W. Alam, and S. A. Ansari, "Selfassembled Cube-like Copper Oxide Derived from a Metal-Organic Framework as a High-Performance Electrochemical Supercapacitive Electrode Material," Sci. Rep., vol. 9, no. 1, p. 9140, Dec. 2019, DOI: 10.1038/s41598-019-45557-6.

18 D. Astruc, "Introduction: Nanoparticles in catalysis," Chem. Rev., 2020, 120(2), 461-463. DOI: 10.1021/acs.chemrev.8b00696.

19 S. Panigrahi et al., Synthesis and size-selective catalysis by supported gold nanoparticles: Study on heterogeneous and homogeneous catalytic process, J. Phys. Chem. C, 2007, 111(12), 4596-4605. DOI: 10.1021/jp067554u.

20 C. V. Rode, M. J. Vaidya, and R. V. Chaudhari, Synthesis of $p$ -aminophenol by catalytic hydrogenation of nitrobenzene, Org. Process Res. Dev., vol. 3, no. 6, pp. 465-470, Nov. 1999, DOI: 10.1021/ op990040r.

$21 \mathrm{~N}$. Comisso et al., Electrodeposition of $\mathrm{Cu}-\mathrm{Rh}$ alloys and their use as cathodes for nitrate reduction, Electrochem. Commun., 2012, 25, 91-93. DOI: 10.1016/j.elecom.2012.09.026.

22 K. B. Narayanan and N. Sakthivel, Synthesis and characterisation of nano-gold composite using Cylindrocladium floridanum and its heterogeneous catalysis in the degradation of 4-nitrophenol, J. Hazard. Mater., 2011, 189(1-2), 519-525. DOI: 10.1016/j.jhazmat.2011.02.069.

23 T.-L. Lai, K.-F. Yong, J.-W. Yu, J.-H. Chen, Y.-Y. Shu, and C.-B. Wang, High efficiency degradation of 4-nitrophenol by microwaveenhanced catalytic method, J. Hazard. Mater., 2011, 185(1), 366-372.x DOI: 10.1016/j.jhazmat.2010.09.044.

24 D. Makovec, M. Sajko, A. Selišnik, and M. Drofenik, Magnetically recoverable photocatalytic nanocomposite particles for water treatment, Mater. Chem. Phys., 2011, 129(1-2), 83-89. DOI: 10.1016/j. matchemphys.2011.03.059.

$25 \mathrm{~S}$. Kumar et al., Facile synthesis of hierarchical $\mathrm{Cu} 2 \mathrm{O}$ nanocubes as visible light photocatalysts, Appl. Catal. B Environ., 2016, 189, 226 232. DOI: 10.1016/j.apcatb.2016.02.038.

26 N. A. Dhas, C. P. Raj, and A. Gedanken, Synthesis, Characterisation, and Properties of Metallic Copper Nanoparticles, Chem. Mater., 1998, 10(5), 1446-1452. DOI: $10.1021 / \mathrm{cm} 9708269$.

27 M. Černík and V. V. Thekkae Padil, Green synthesis of copper oxide nanoparticles using gum karaya as a biotemplate and their antibacterial application, Int. J. Nanomedicine, 2013, 8, 889-898. , DOI: 10.2147/IJN.S40599.

28 M. C. Biesinger, Advanced analysis of copper X-ray photoelectron spectra, Surf. Interface Anal., 2017, 49(13), 1325-1334. DOI: 10.1002/ sia.6239.

29 H. K. A. J. V. K. M. H. Sabzevar, Facile synthesis of copper oxide nanoparticles using copper hydroxide by mechanochemical process, J. Ultrafine Grained Nanostructured Mater., vol. 48, pp. 37-44, 2015, DOI: 10.7508/jufgnsm.2015.01.006.

30 G. Cheng and A. R. H. Walker, Transmission electron microscopy characterisation of colloidal copper nanoparticles and their chemical reactivity, Anal. Bioanal. Chem., 2009, 396(3), 1057-1069. DOI: 10.1007/ s00216-009-3203-0.

31 L. Chen et al., Copper salts mediated morphological transformation of $\mathrm{Cu}_{2} \mathrm{O}$ from cubes to hierarchical flower-like or microspheres and their supercapacitors performances, Sci. Rep., 2015, 5(1), 9672. DOI: 10.1038/srep09672.

32 J. Tauc, Amorphous and Liquid Semiconductors. Springer, Boston, MA US, 1974.

33 D. P. Dubal, G. S. Gund, C. D. Lokhande, and R. Holze, CuO cauliflowers for supercapacitor application: Novel potentiodynamic deposition, Mater. Res. Bull., 2013, 48(2), 923-928. DOI: 10.1016/j. materresbull.2012.11.081.

34 K. Borgohain, J. B. Singh, M. V. Rama Rao, T. Shripathi, and S. Mahamuni, Quantum size effects in $\mathrm{CuO}$ nanoparticles, Phys. Rev. B, 2000, 61(16), 11093-11096. DOI: 10.1103/PhysRevB.61.11093.

35 E. C. Heltemes, Far-infrared properties of cuprous oxide, Phys. Rev., 1966, 141(2), 803-805. DOI: 10.1103/PhysRev.141.803.

36 N. Sreeju., A. Rufus, and D. Philip, Microwave-assisted rapid synthesis of copper nanoparticles with exceptional stability and their multifaceted applications, J. Mol. Liq., 2016, 221, 1008-1021. DOI: 10.1016/j.molliq.2016.06.080.

37 S. L. Keenan, K. P. Peterson, K. Peterson, and K. Jacobson, Determination of Hammett equation rho constant for the Hydrolysis of p-nitrophenyl benzoate esters," J. Chem. Educ., 2008, 85(4), 558. DOI: 10.1021/ed085p558.

38 Y. Jiang, X. Zhu, H. Li, and J. Ni, Effect of nitro substituent on electrochemical oxidation of phenols at boron-doped diamond anodes, Chemosphere, 2010, 78(9), 1093-1099. DOI: 10.1016/j. chemosphere.2009.12.036.

39 L. Li, C. Nan, Q. Peng, and Y. Li, Selective synthesis of $\mathrm{Cu}_{2} \mathrm{O}$ nanocrystals as shape-dependent catalysts for oxidative arylation of phenylacetylene," Chem. - A Eur. J., 2012, 18(34), 10491-10496. DOI: 10.1002/chem.201200567. 


\section{Supplementary material to:}

E. Erasmus

Truncated edge cuprous oxide cube architecture for reduction of nitrophenols

S. Afr. J. Chem., 2021, 75, 106-110 


\title{
Truncated edge cuprous oxide cube architecture for reduction of nitrophenols
}

\author{
Elizabeth Erasmus
}

\section{SUPPLEMENTARY INFORMATION}

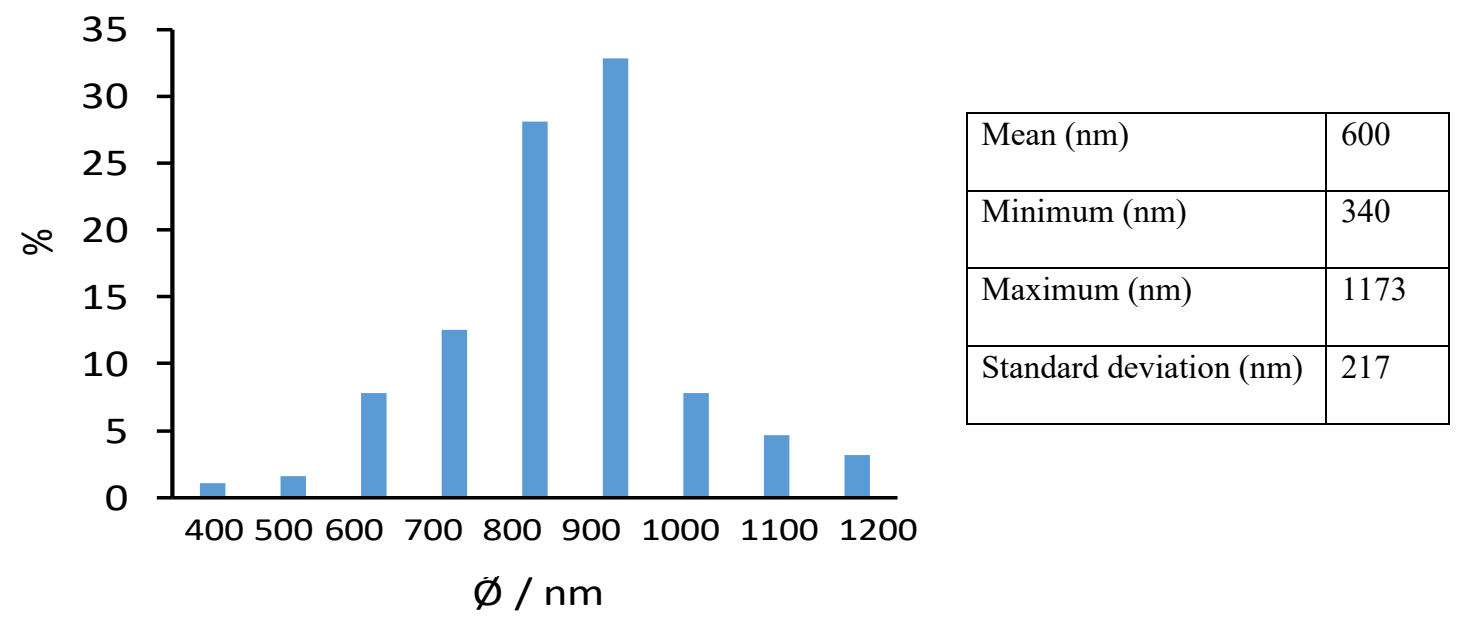

Figure S1. Left: The histogram showing the distribution of the measured particle sizes. Right: The table showing the mean, minimum and maximum diameter (in $\mathrm{nm}$ ) as well as the standard deviation of the particles as measured from the TEM images of the $\mathrm{Cu}$-oxide nanocrystals.
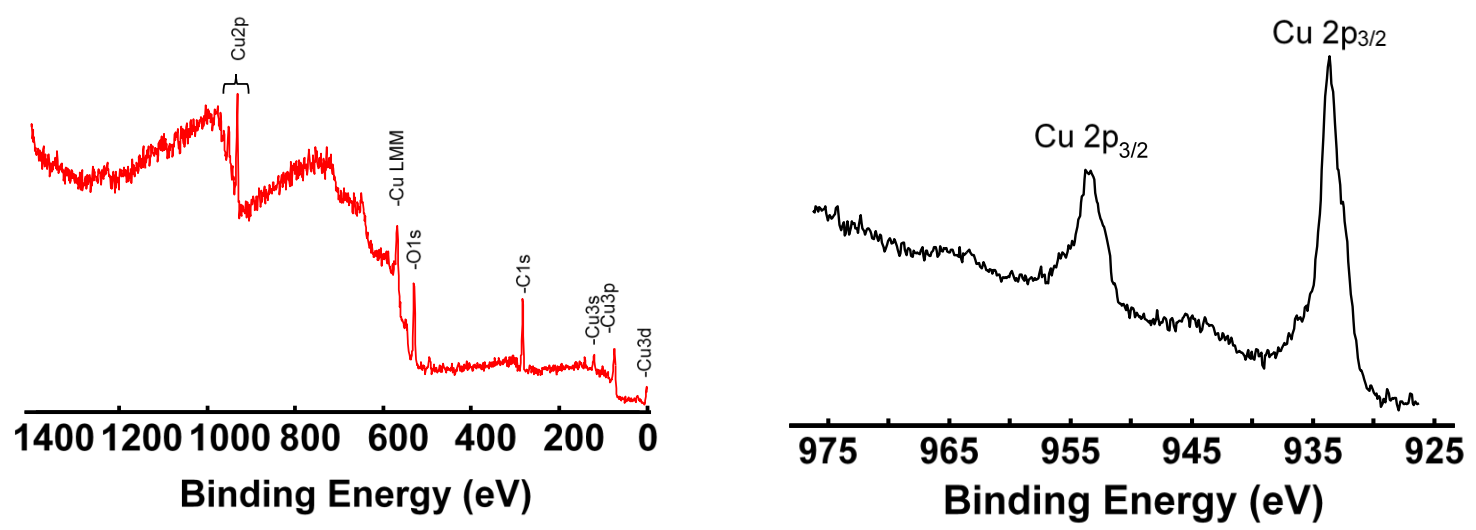

Figure S2. XPS Wide scan of the Cu-oxide (Left) and XPS detail scan of the $\mathrm{Cu} 2 \mathrm{p}$ area of the truncated $\mathrm{Cu}$-oxide nanocrystal (Right). 


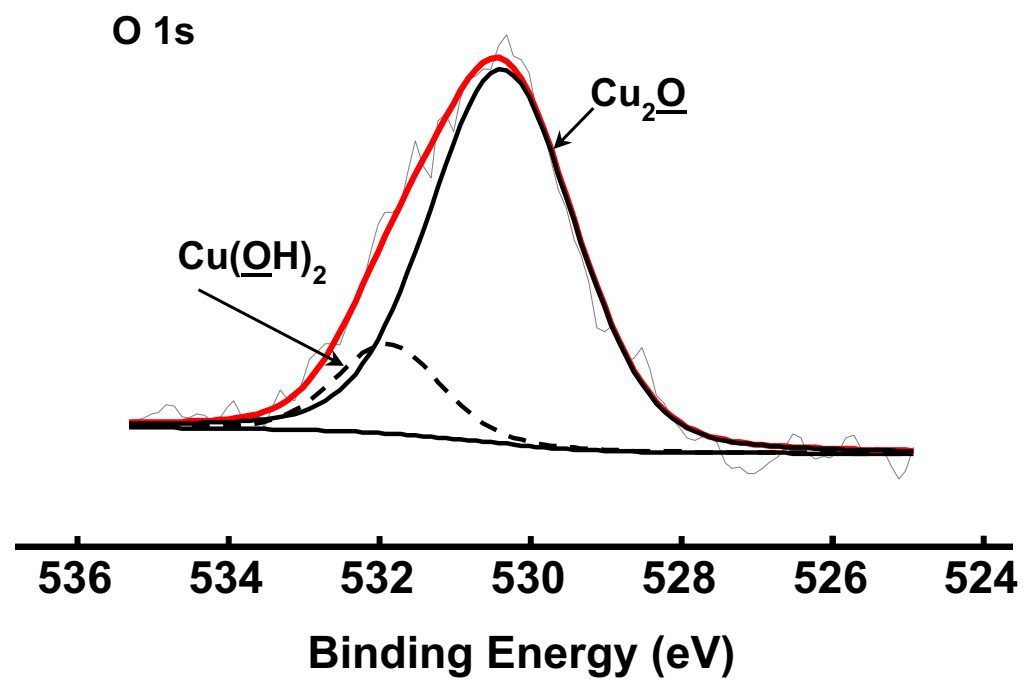

Figure S3. XPS detail scan of the $\mathrm{O} 1$ s area of the truncated $\mathrm{Cu}$-oxide nanocrystals, showing the simulated fits.

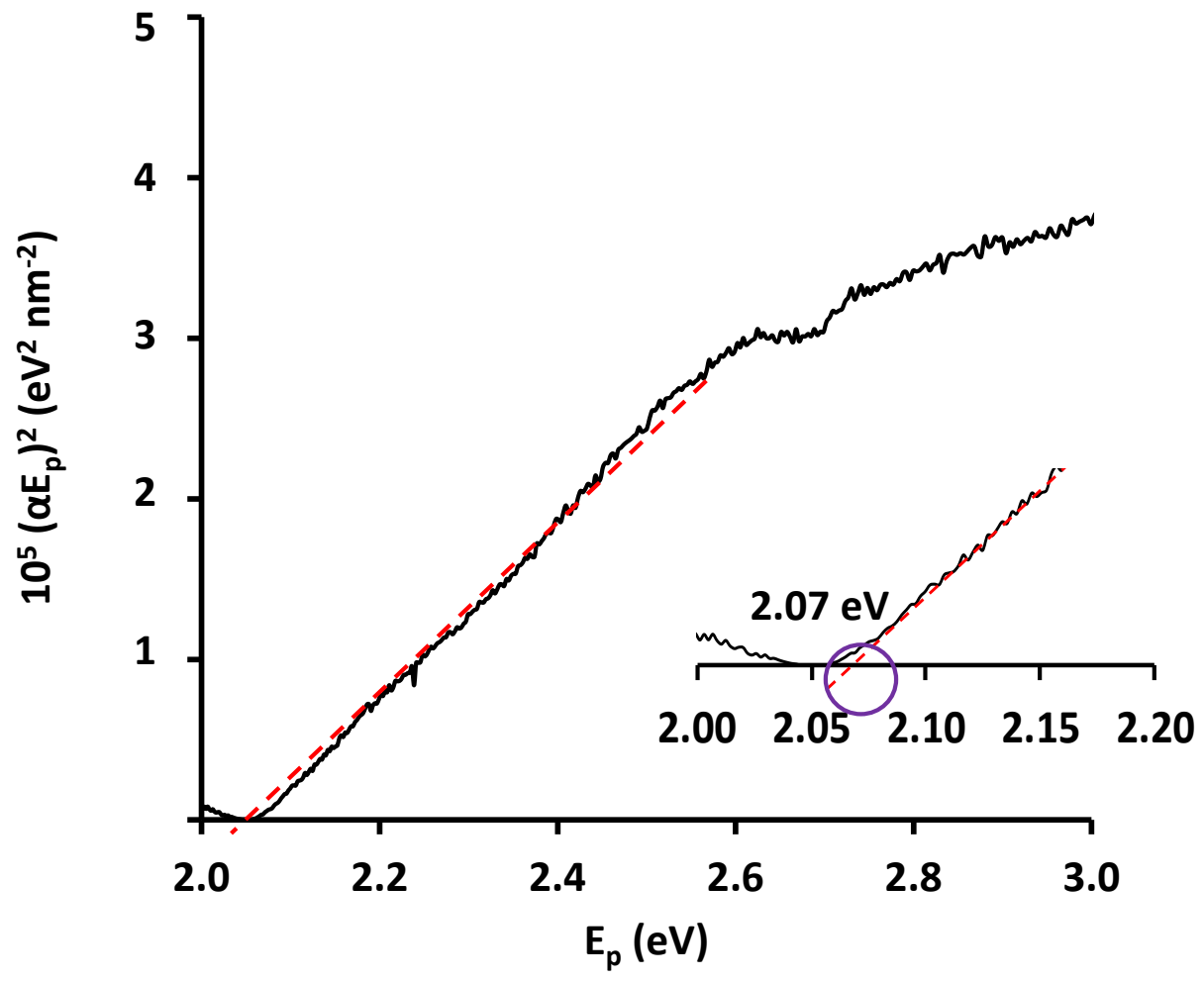

Figure S4. The Tauc plot of $\left(\alpha E_{\mathrm{p}}\right)^{2}$ vs $E_{\mathrm{p}}$, corresponding to the UV-Vis spectrum in Figure 3. 


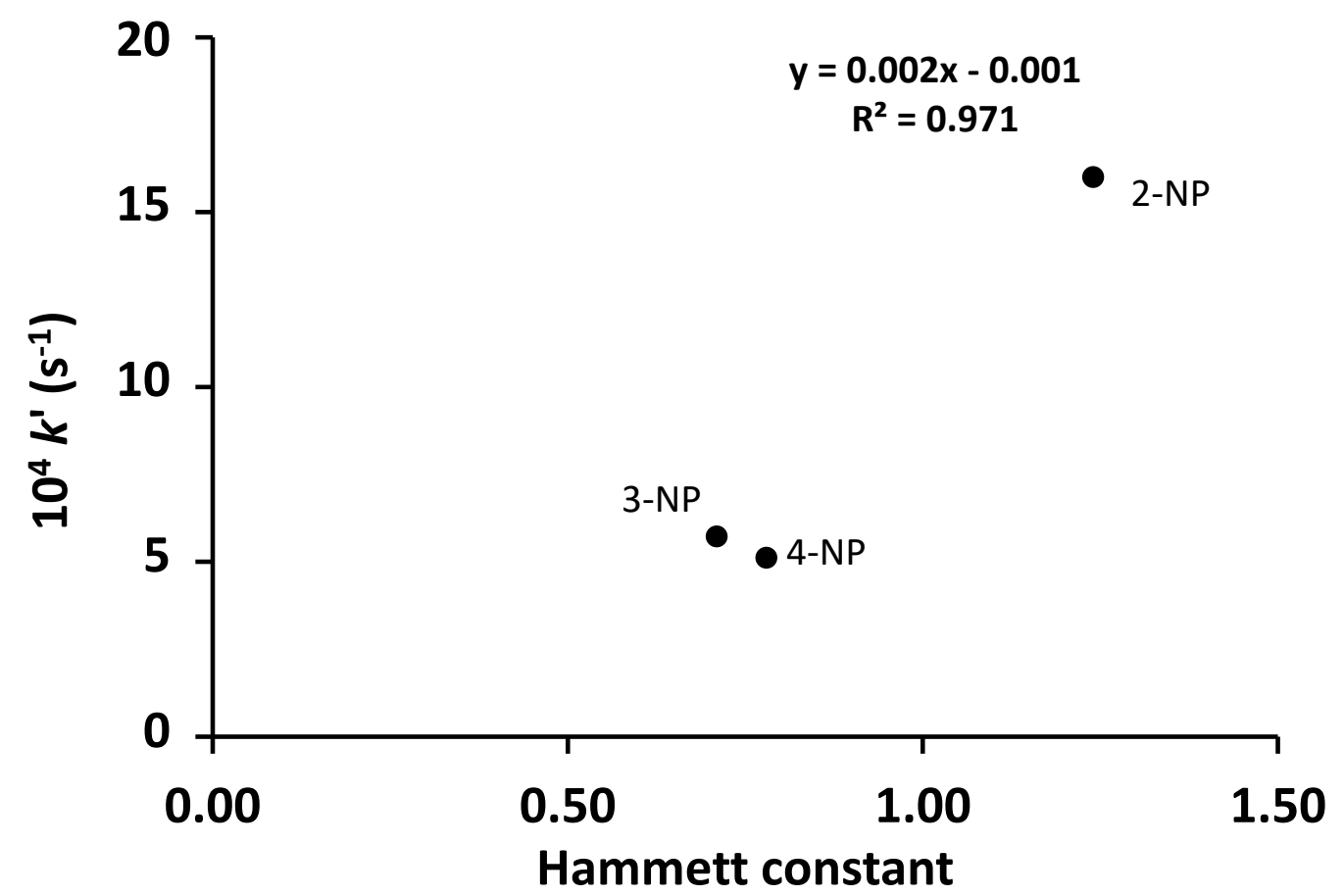

Figure S5. The relationship between the Hammett constants and the apparent pseudo-firstorder rate constant, $k^{\prime}$, of the catalytic reduction of 2-, 3- and 4-nitrophenol over the truncated cubic $\mathrm{Cu}$-oxide nanocrystals using $\mathrm{NaBH}_{4}$ as the reducing agent. 